\title{
Renal Anemia Treatment with ESA in Hemodialysis Patients in Relation to Early versus Late Referral in Everyday Clinical Practice in Central and Eastern European Countries: Baseline Data
}

\author{
Jolanta Malyszko ${ }^{a} \quad$ Maciej Drozdz ${ }^{b}$ Agnieszka Zolkiewicz ${ }^{c} \quad$ Boleslaw Rutkowski $^{d}$ \\ a Department of Nephrology and Transplantology, Medical University, Bialystok, ${ }^{\mathrm{b}}$ Department of Nephrology, \\ Collegium Medicum, Jagiellonian University, Cracow, ' $R$ Roche Pharmaceutical Company, Warsaw, and \\ ${ }^{\mathrm{d} D e p a r t m e n t}$ of Nephrology, Transplantology and Internal Diseases, Medical University, Gdansk, Poland
}

\section{Key Words}

Chronic kidney disease $\cdot$ Renal anemia $\cdot$ Hemodialysis •

Erythropoiesis-stimulating agents $\cdot$ Central and Eastern

European countries

\begin{abstract}
The aim of the study was to collect retrospective data on renal anemia management, comorbidities and prospective data on 12-month standard care erythropoiesis-stimulating agent (ESA) therapy used in 398 hemodialyzed patients in selected Central and Eastern European countries (50 centers in 3 countries). Patients were divided into three groups according to ESA therapy start: group A-ESA (after start of hemodialysis, HD), B-ESA (within 3 months from start of HD), C-ESA (more than 3 months before HD). At the chronic kidney disease diagnosis, hemoglobin in all patients was $10.3 \pm 2.3$ $\mathrm{g} / \mathrm{dl}$; however, ferritin, iron, TSAT were within reference limits. Early ESA therapy (C) was administered to $10 \%$ of patients only. $47 \%$ of patients received ESA after start of dialysis. Before study, the mean weekly ESA dose in group $C$ was statistically lower than in groups $B$ and $A(p<0.001)$. At baseline visit, hemoglobin in group A patients was slightly lower than in group $B$ and $C$ patients $(p=0.025)$. In conclusion, in Central and Eastern European countries renal anemia therapy with ESA starts shortly before or after start of HD. This highlights
\end{abstract}

important differences in standard care in Eastern Europe. However, paradoxically, due to the tight reimbursement policy we foresee the clinical implications of the TREAT trial for the chronic kidney disease population.

Copyright $\odot 2011$ S. Karger AG, Basel

\section{Introduction}

Chronic kidney disease (CKD) is defined either as kidney damage or a glomerular filtration rate (GFR) of less than $60 \mathrm{ml} / \mathrm{min}$ for three months or more [1]. A normochromic, normocytic anemia is present in the majority of CKD patients, and begins during early renal insufficiency when the GFR falls below age-adjusted normal limits [2]. The diagnosis of anemia of CKD, so-called 'renal anemia', is usually made by excluding other potential causes of anemia in a patient with CKD, or in situations where there is moderate impairment of renal function (GFR 30$59 \mathrm{ml} / \mathrm{min}$ ) and anemia is anticipated. In the setting of CKD, anemia has a number of potentially deleterious effects, including impairment of tissue oxygen delivery, increased cardiac output and left ventricular hypertrophy predisposing to congestive heart failure [3], cognitive decline, sexual dysfunction, and depression of immune responsiveness. The recent availability of erythropoietin

\section{KARGER}

Fax +4161306 1234 E-Mail karger@karger.ch www.karger.com

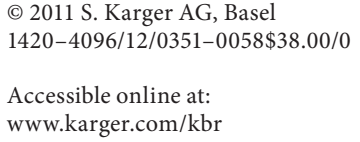

Prof. Jolanta Malyszko

Department of Nephrology and Transplantology, Medical University

Zurawia 14

PL-15-540 Bialystok (Poland)

Tel. +48 85740 9464, E-Mail jolmal@ poczta.onet.pl 
therapy has revolutionized management of anemia in CKD. It has significantly lessened the need to administer multiple blood transfusions and minimized the associated risks of transfusion, including alloimmunization, iron overload and transmission of infectious diseases. Administration of erythropoiesis-stimulating agents (ESA) to increase $\mathrm{Hb}$ concentrations from lower values to $>10-11 \mathrm{~g} / \mathrm{dl}$ significantly reduces the cardiovascular complications of renal anemia, and reduces the frequency of chronic heart failure and hospitalization among predialysis and dialysis-dependent patients $[4,5]$. However, the recent CHOIR [6], CREATE [7] and TREAT [8] trials fail to demonstrate the reduction in cardiovascular complications in CKD patients in the high hemoglobin arm. Although mortality among CKD patients is high, recent studies have highlighted a substantial variability in outcome between centers and between countries $[9,10]$. At present, the reason for differences in outcome between centers has not been fully explained. Only in the ORAMA study was a comparison between current management of renal anemia in both CKD and dialysis patients in Eastern and Western European countries performed [11]. The authors reported that baseline hemoglobin values in Eastern Europe were lower than in Western Europe. In the GAIN study [12] involving only hemodialysis (HD) subjects treated with any ESA for at least 12 weeks, and for 18 months with epoetin beta, there were regional differences between Balkan, Baltic, Eastern, Southern and Western Europe. However, these data were not analyzed. Due to the different reimbursement policies and reported lower hemoglobin levels in Eastern Europe as well as lower prevalence of diabetic nephropathy [11, 13], in this study we took a different approach. We designed multicenter, open-label, observational study to assess the impact of early vs. late referral on the effectiveness of renal anemia treatment with ESA in 3 groups of HD patients (treated with ESA less than 3 months before HD, treated with ESA more than 3 months before HD and not treated with ESA before HD) as well as whether treatment with ESA in HD patients can influence the number of cardiovascular events, deaths and hospitalization for $\mathrm{CV}$ and other events in Central and Eastern European (CEE) countries. We formulated the following hypotheses: group A (not treated with ESA) patients will have more profound anemia at baseline than patients in group $B$ (treated with ESA less than 3 months before HD), and group B patients will have more profound anemia than patients from group C (treated with ESA more than 3 months before HD); the baseline differences in anemia parameters will decrease with the time of the study, and at the end of the study no differences between the groups will be observed (end of study anemia $\mathrm{A}$ = end of study anemia $\mathrm{B}=$ end of study anemia $\mathrm{C}$ ); early referral to ESA therapy decreases the number of cardiovascular events (CV events group A $>C V$ events group B $>C V$ events group C). We also looked at the kidney function at the time of diagnosis of CKD and the start of ESA therapy, including the new CKD-EPI formula. Herein, we present the baseline data of the studied groups.

\section{Patients and Methods}

Patients suitable for the study had to fulfill the following inclusion criteria: stable hemodialyzed patients with renal anemia who were no longer than 12 months on HD and who were on ESA therapy; no fluctuation of $\mathrm{Hb}$ more than $2 \mathrm{~g} / \mathrm{dl} / \mathrm{month}$ within the last 3 months of ESA treatment; adult (age $\geq 18$ years); signed informed consent. 50 centers in 3 countries participated in the study. 398 hemodialyzed patients (231 males, 167 females) aged 19-90 years $(57.5 \pm 14.7)$ on standard ESA therapy for chronic renal anemia were recruited. The following retrospective and prospective parameters had been collected during the study and were analyzed. Retrospective parameters: the date of CKD diagnosis (Hb concentration, iron concentration; source of referral to nephrologists; the date of start of predialysis care (Hb concentration, iron concentration, serum creatinine and eGFR calculated according to Cockcroft-Gault [14], Modification of Diet in Renal Disease (MDRD) [15] and CKD-EPI formulae [16]); period of renal anemia treatment; date of start of HD; all major CV events in patient's history (MI, PCI, coronary artery bypass grafting, stroke, TIA). The data were collected in electronic Data Capture system. Data were verified for logical and medical consistency according to the instructions provided in CTAP. In the case of inconsistencies, data query was generated and was sent for investigator's review. A part of problems was resolved; however, some queries were not addressed by investigators. Unresolved issues were related to missing data allowing to allocate patient to specific study group (15 patients), discrepancies between laboratory results and acceptable range of results, and AE description. All available and logically acceptable data were analyzed.

Patients were divided into three groups: group A - patients not treated with ESA before start of dialysis; group B - patients who had started ESA therapy within 3 months from start of dialysis; group C - patients who had started the ESA therapy more than 3 months before start of dialysis.

Comparisons were performed for all patients allocated to one of the groups. Patients without allocation were excluded from analysis.

Statistical Analysis

The data recorded in the database were provided for analysis in the Excel format.

The data were analyzed using SAS statistical software. The $\chi^{2}$ test was used for analysis of qualitative data and the Kruskal-Wallis test for quantitative data. $p$ value $\leq 0.05$ was defined as statistically significant. 
Fig. 1. Patient status at 12 months of the study.
Fig. 2. Distribution of the diagnosis leading to renal failure.
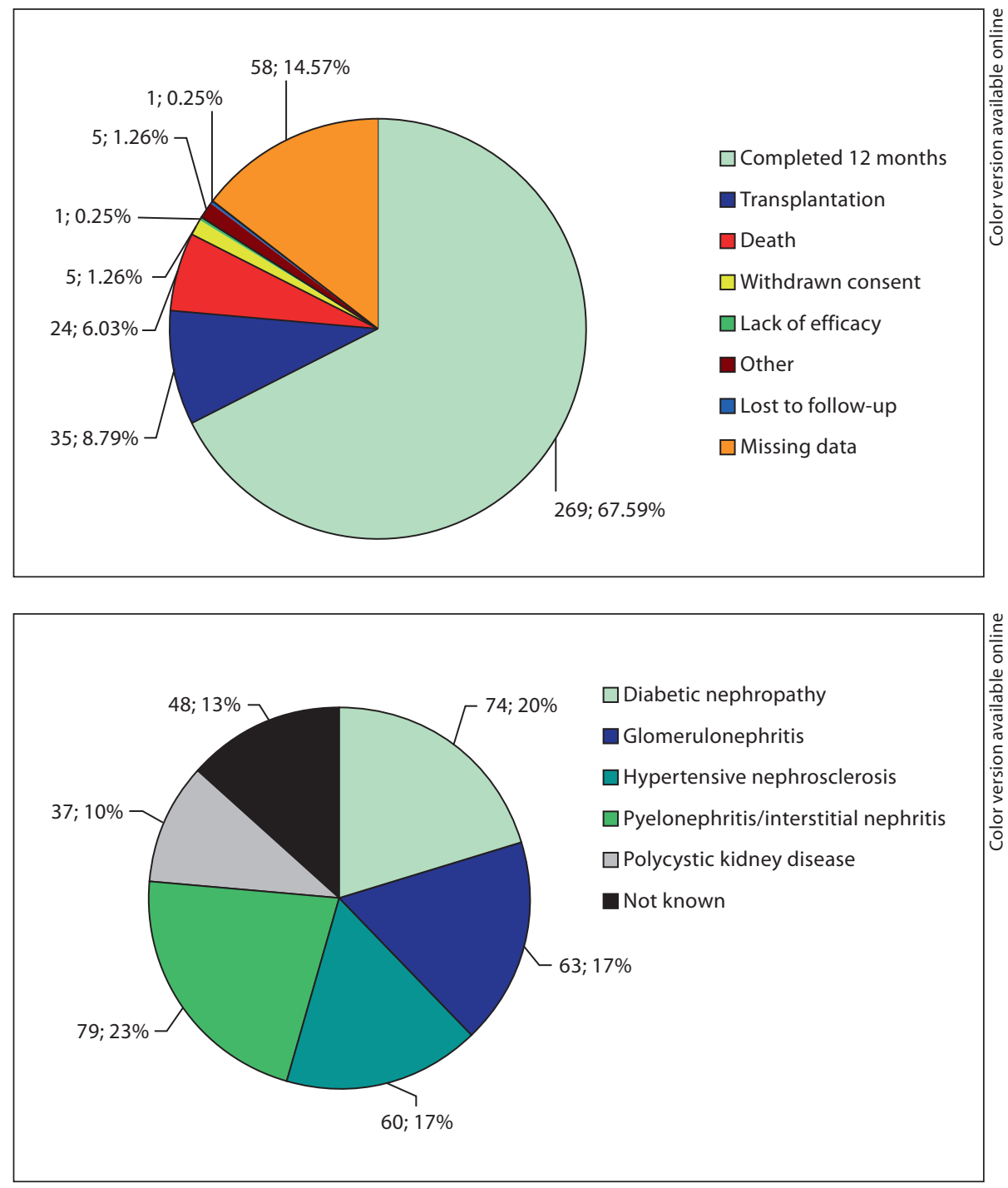

\section{Results}

\section{Baseline Patient Characteristics}

Fifty centers participated in the study. The number of patients recruited at a single center varied from 1 to 23 (mean $8 \pm 5$ ). The highest number of patients (267) was recruited in 30 centers in Poland (mean number of patients per center $9 \pm 5$ ). 12 centers in Latvia recruited 81 patients $(7+5)$ and 8 centers in Serbia recruited 50 patients $(6 \pm 3) .269$ patients completed 12 months of therapy. The reasons for study discontinuation are provided in figure 1.

Based on the start dates of ESA and dialysis therapy, patients were allocated to groups A, B and C. Group A: 180 subjects (106 males, 74 females) aged 19-86 years
(56.2 \pm 14.4 years); group B: 164 subjects (94 males, 70 females) aged 19-90 years (57.6 \pm 14.9 years); group C: 39 subjects ( 21 males, 18 females) aged $20-86$ years (61.8 \pm 16 years).

No statistically significant differences between groups A, B and C in age and sex distributions were found. 15 patients could not be classified into any of the groups and were excluded from comparative analysis. Groups A, B and $\mathrm{C}$ did not differ in baseline values of arterial blood pressure, body weight or height and BMI.

\section{Causes of CKD}

The reasons for CKD were equally distributed (fig. 2).

The diagnosis of CKD was established at the age between 6.5 and 86.3 years $(53.6 \pm 15.7)$. No statistically 


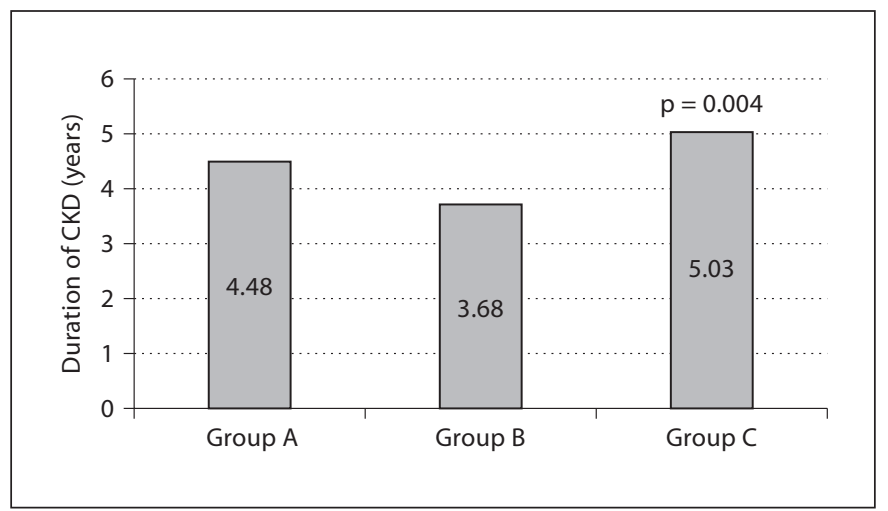

Fig. 3. Duration of CKD in patients from groups $\mathrm{A}, \mathrm{B}$ and $\mathrm{C}$.

significant differences in the age at CKD onset were noted between groups A, B and C. CKD was ongoing for the period from few days to 41 years before study start (4.2 \pm 5.6). The duration of CKD in group $C$ patients was significantly longer than in groups B and A (fig. 3).

\section{Medical History and Concomitant Diseases}

The protocol predefined the categories of concomitant diseases of special interest (fig. 4). Compared with groups $A$ and $C$, group $B$ had a significantly lower rate of patients with left ventricular hypertrophy (53 and 64 vs. $39 \%$, respectively, $\mathrm{p}=0.004)$ and secondary hyperparathyroidism ( 43 and 44 vs. $25 \%, \mathrm{p}=0.001$ ). The frequency of remaining concomitant diseases did not differ between groups $\mathrm{A}, \mathrm{B}$ and $\mathrm{C}$.

Forty $(10 \%)$ patients had a history of myocardial infarct. Other serious heart episodes were less frequent (fig. 5). The rate of patients with the history of heart disease did not differ between groups A, B and C.

\section{Retrospective Data on CKD Diagnosis}

At the CKD diagnosis, the mean hemoglobin concentration in all patients was below lower reference limit (10.3 $\pm 2.3 \mathrm{~g} / \mathrm{dl})$; however, the ferritin concentration $(222 \pm 182$ $\mu \mathrm{g} / \mathrm{dl})$, serum iron concentration $(10.4 \pm 5.5 \mu \mathrm{mol} / \mathrm{l})$ and transferrin saturation $(28 \pm 18 \%)$ were within reference limits (table 1). No differences in these parameters were observed between groups A, B and C. Patient weight at the onset of the disease varied from 24 to $130 \mathrm{~kg}$ (mean $74 \pm$ $17 \mathrm{~kg}$ ), and the body weight at the onset of renal failure was comparable in all groups. Mean creatinine concentration at the disease diagnosis was $4.7 \pm 3.6 \mathrm{mg} / \mathrm{dl}$. GFR according to the MDRD formula was $21.8 \pm 17.9 \mathrm{ml} / \mathrm{min}$ and creatinine clearance according to Cockcroft-Gault formu-
Table 1. Baseline patient characteristics in the 3 groups

\begin{tabular}{|c|c|c|c|c|c|}
\hline & \multirow{2}{*}{$\begin{array}{l}\text { Total } \\
(\mathrm{n}=398)\end{array}$} & \multicolumn{3}{|l|}{ Group } & \multirow[t]{2}{*}{$\mathrm{p}$} \\
\hline & & $A(n=186)$ & $B(n=165)$ & $C(\mathrm{n}=38)$ & \\
\hline \multicolumn{5}{|l|}{ Sex } & 0.9266 \\
\hline Male & 231 & 109 & 95 & 21 & \\
\hline Female & 167 & 77 & 70 & 17 & \\
\hline \multicolumn{5}{|l|}{ Age } & 0.0648 \\
\hline Mean & 57.49 & 56.42 & 57.60 & 62.05 & \\
\hline SD & 14.71 & 14.33 & 14.89 & 16.48 & \\
\hline Median & 58.00 & 58.00 & 58.00 & 66.50 & \\
\hline \multicolumn{5}{|l|}{ Height } & 0.8144 \\
\hline Mean & 168.62 & 168.93 & 168.04 & 169.42 & \\
\hline SD & 9.89 & 9.65 & 10.16 & 10.50 & \\
\hline Median & 168.00 & 169.00 & 169.00 & 167.00 & \\
\hline \multicolumn{5}{|l|}{ Systolic BP } & 0.6756 \\
\hline Mean & 138.19 & 138.53 & 138.28 & 135.92 & \\
\hline SD & 20.63 & 21.28 & 20.79 & 18.34 & \\
\hline Median & 140.00 & 140.00 & 139.00 & 137.50 & \\
\hline \multicolumn{5}{|l|}{ Diastolic BP } & 0.1629 \\
\hline Mean & 79.63 & 79.22 & 80.70 & 77.47 & \\
\hline SD & 11.46 & 11.99 & 11.49 & 9.17 & \\
\hline Median & 80.00 & 80.00 & 80.00 & 80.00 & \\
\hline \multicolumn{5}{|l|}{ Weight } & 0.1390 \\
\hline Mean & 73.08 & 73.30 & 71.88 & 76.66 & \\
\hline SD & 15.57 & 15.10 & 16.23 & 16.23 & \\
\hline Median & 71.00 & 72.00 & 70.00 & 75.00 & \\
\hline \multicolumn{5}{|l|}{ BMI } & 0.1729 \\
\hline Mean & 25.67 & 25.67 & 25.42 & 26.65 & \\
\hline SD & 4.96 & 4.92 & 5.14 & 4.75 & \\
\hline Median & 24.64 & 25.12 & 24.17 & 25.81 & \\
\hline
\end{tabular}

la $24.6 \pm 205 \mathrm{ml} / \mathrm{min}$. Group C patients had slightly lower creatinine concentration and significantly higher GFR/ creatinine clearance calculated by MDRD or CockcroftGault formula than patients from groups A and B. The diagnosis of CKD was established by nephrologist in 142 (35.7\%) and by internist in 141 (35.4\%) patients. Causes of $\mathrm{CKD}$ and concomitant disease in the 3 studied groups are given in the tables 2 and 3 , respectively.

\section{Retrospective Data on Predialysis Care}

No statistically significant differences in hematology parameters, creatinine concentration or creatinine clearance between groups A, B and C were observed in the predialysis period.

\section{Retrospective Data on HD Start}

HD therapy in the whole group started at the mean age of $57.4 \pm 14.9$ years. No differences in mean age at HD start were observed between groups A, B and C. The 


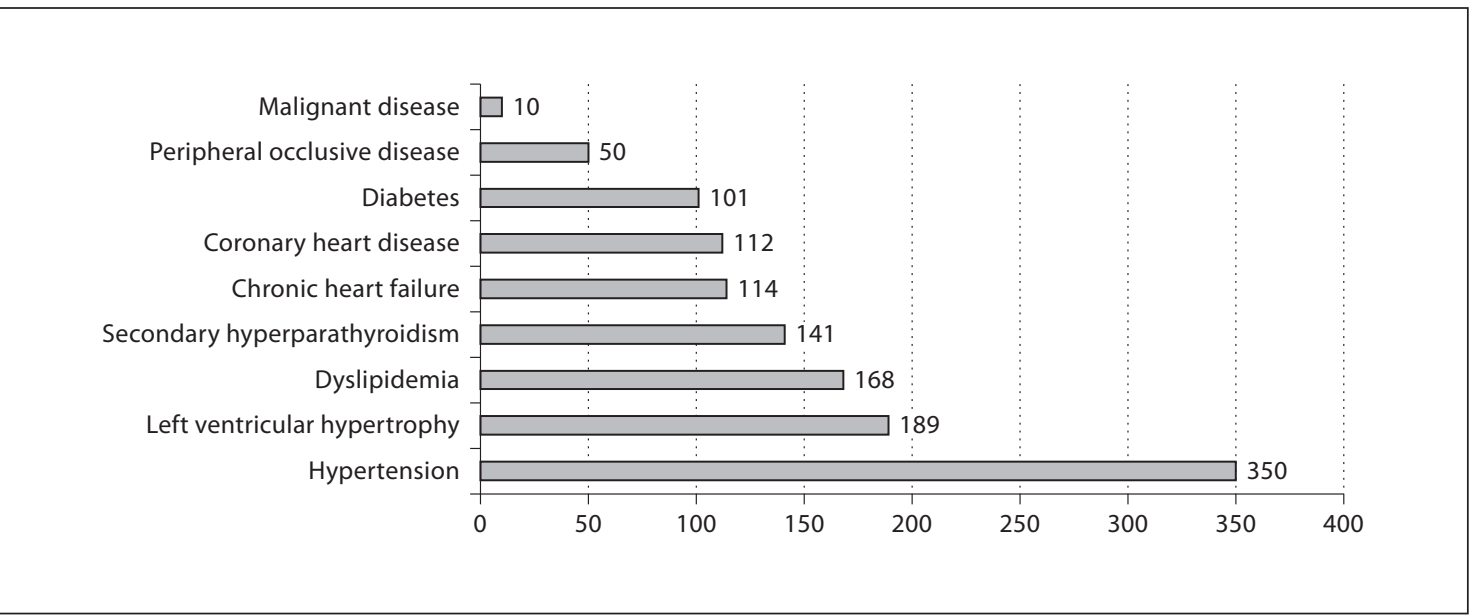

Fig. 4. Number of patients with presence of predefined concomitant disease.

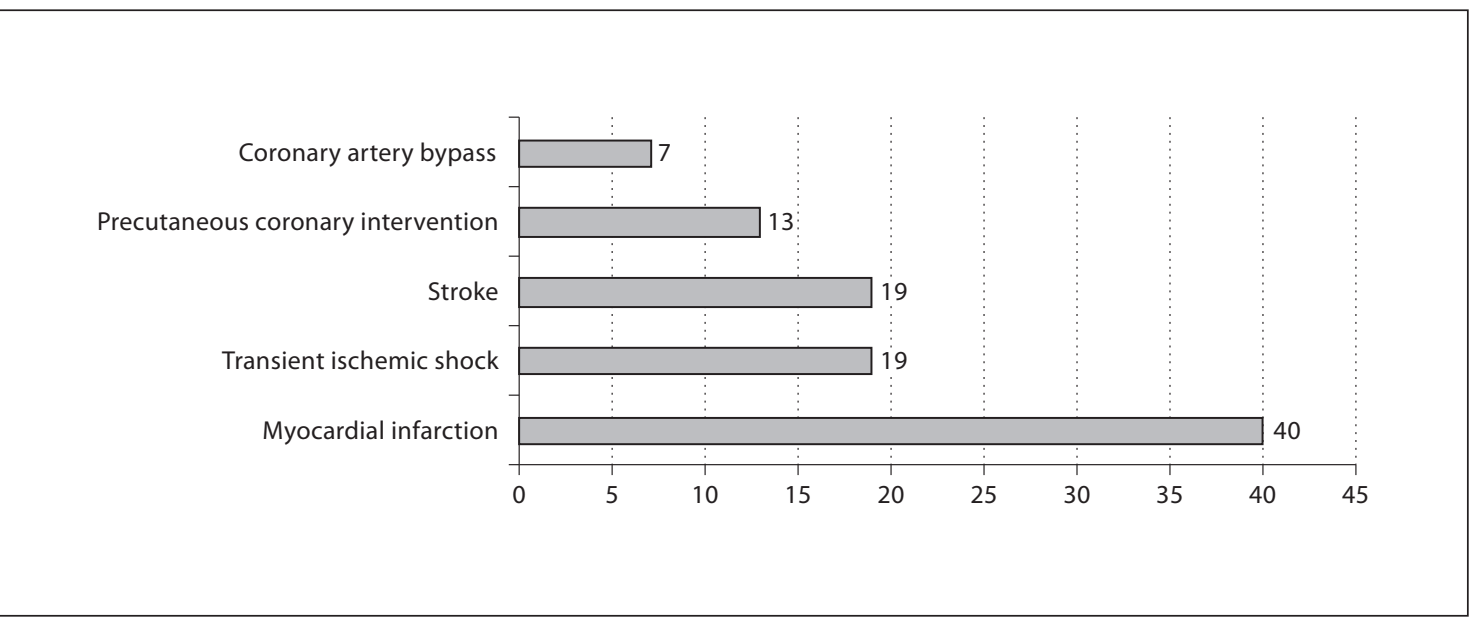

Fig. 5. Frequency of cardiovascular episodes in patient history.

Table 2. Causes of CKD in the 3 studied groups

\begin{tabular}{llllll}
\hline & $\begin{array}{l}\text { Total } \\
(\mathrm{n}=398)\end{array}$ & Group & & $\mathrm{p}$ \\
\cline { 3 - 4 } & & $\mathrm{A}(\mathrm{n}=186)$ & $\mathrm{B}(\mathrm{n}=165)$ & $\mathrm{C}(\mathrm{n}=38)$ & \\
\hline Diabetic nephropathy & $75(18.84)$ & $30(16.13)$ & $36(21.82)$ & $8(21.05)$ & 0.6795 \\
Glomerulonephritis & $64(16.08)$ & $30(16.13)$ & $23(13.94)$ & $9(23.68)$ & \\
Hypertensive nephrosclerosis & $61(15.33)$ & $35(18.82)$ & $22(13.33)$ & $3(7.89)$ \\
Pyelonephritis/interstitial nephritis & $79(19.85)$ & $36(19.35)$ & $31(18.79)$ & $9(23.68)$ \\
Polycystic kidney disease & $38(9.55)$ & $18(9.68)$ & $17(10.30)$ & $2(5.26)$ \\
Not known & $48(12.06)$ & $24(12.90)$ & $19(11.52)$ & $4(10.53)$ \\
Other & $33(8.29)$ & $13(6.99)$ & $17(10.30)$ & $3(7.89)$ \\
\hline
\end{tabular}

Figures in parentheses indicate percentages. 


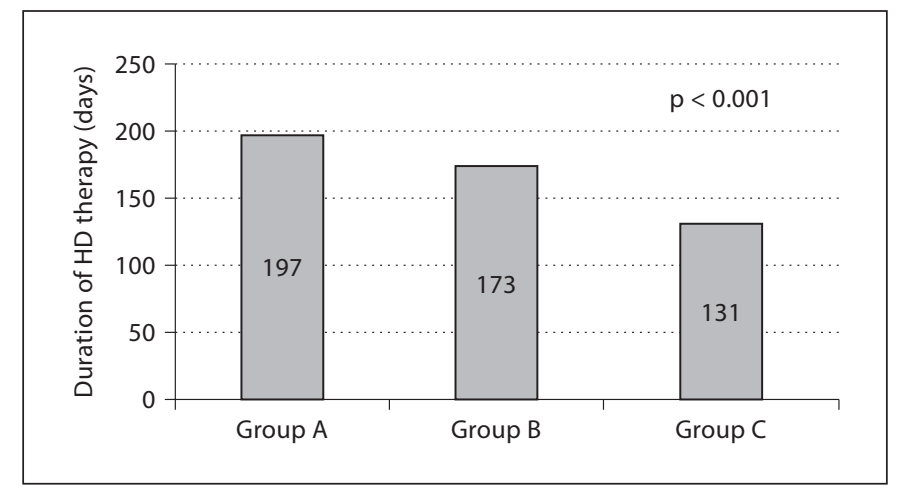

Fig. 6. Duration of HD in patients from groups A, B and C.

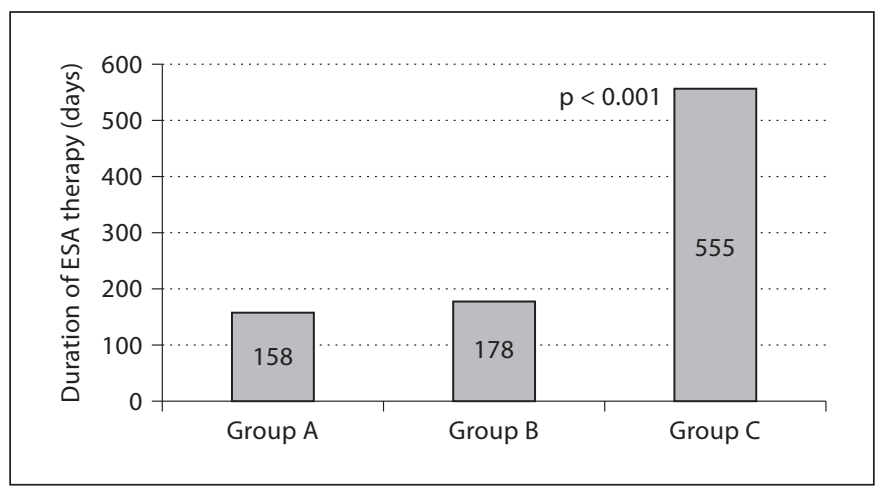

Fig. 7. Duration of prestudy ESA therapy.

Table 3. Concomitant diseases in the 3 studied groups

\begin{tabular}{lccccc}
\hline & \multirow{2}{*}{$\begin{array}{l}\text { Total } \\
(\mathrm{n}=398)\end{array}$} & \multicolumn{2}{l}{ Group } & & $\mathrm{p}$ \\
\cline { 5 - 6 } & & $\mathrm{A}(\mathrm{n}=186)$ & $\mathrm{B}(\mathrm{n}=165)$ & $\mathrm{C}(\mathrm{n}=38)$ & \\
\hline Diabetes & $102(25.63)$ & $42(22.58)$ & $48(29.09)$ & $11(28.95)$ & 0.3460 \\
Hypertension & $354(88.94)$ & $162(87.1)$ & $147(89.09)$ & $37(97.37)$ & 0.1834 \\
Coronary heart disease & $113(28.39)$ & $53(28.49)$ & $42(25.45)$ & $15(39.47)$ & 0.2230 \\
Chronic heart failure & $115(28.89)$ & $52(27.96)$ & $43(26.06)$ & $17(44.74)$ & 0.0680 \\
Left ventricular hypertrophy & $192(48.24)$ & $98(52.69)$ & $65(39.39)$ & $24(63.16)$ & 0.0066 \\
Peripheral occlusive disease & $50(12.56)$ & $26(13.98)$ & $17(10.3)$ & $7(18.42)$ & 0.3296 \\
Dyslipidemia & 171 & 89 & 64 & 18 & 0.2109 \\
\hline
\end{tabular}

Figures in parentheses indicate percentages.

mean duration of the dialysis treatment in the whole group was $180 \pm 105$ days. Patients from group A were longer on dialysis therapy than patients from groups $\mathrm{B}$ and C (fig. 6).

The mean value of hemoglobin concentration in the whole group was below lower reference limit $(9.26 \pm 1.7$ $\mathrm{mg} / \mathrm{dl})$. Mean serum iron concentration $(10.2 \pm 5.78$ $\mu \mathrm{mol} / \mathrm{l})$, and transferrin saturation $(23.65 \pm 16.4 \%)$ were close to the lower reference limit value. No statistically significant differences in hematology parameters were observed between groups A, B and C.

\section{Retrospective Data on ESA Therapy Start}

Mean duration of prestudy ESA therapy in the whole group was $207 \pm 203$ days. Patients from group C received ESA for statistically significantly longer than those from groups A and B (fig. 7).

As per protocol, none of patients from group A received ESA before HD. ESA in this group started at a mean of $39 \pm 17$ days after start of HD. Patients from group B received ESA within 90 days before dialysis ( $5 \pm$ 14 days), and those from group $\mathrm{C}$ had received ESA more than 90 days before start of HD (423 \pm 426 days).

The most frequently used ESA formulation was Epo beta - NeoRecormon (70\%). Epo alpha was used in 16\% and darbepoetin alpha in $14 \%$ of patients. The subcutaneous route of administration was used in $62 \%$ and the intravenous route in $38 \%$ of patients. The rate of patients receiving ESA subcutaneously in group C (92\%) was significantly higher than in groups $\mathrm{A}$ and $\mathrm{B}$. The mean weekly dose of ESA in all patients was 5,621 \pm 3,271 units. Mean prestudy weekly dose of ESA in group C was statistically lower than in group A and B patients $(3,823$ $\pm 3,168$ vs. $5,275 \pm 2,915$ and $6,426 \pm 3,441$ units/week, respectively, $\mathrm{p}<0.001$ ).

At the start of ESA therapy, mean hemoglobin concentration was $9.24 \pm 1.42 \mathrm{~g} / \mathrm{dl}$, ferritin $245.6 \pm 245.8 \mathrm{mg} /$ $\mathrm{dl}$, serum iron $11.29 \pm 6.25 \mu \mathrm{mol} / \mathrm{l}$ and transferrin satu- 
Table 4. Summary data at prestudy ESA start

\begin{tabular}{|c|c|c|c|c|c|}
\hline \multirow{2}{*}{$\begin{array}{l}\text { GFR/ } \\
\text { creatinine } \\
\text { clearance, } \\
\mathrm{ml} / \mathrm{min}\end{array}$} & \multirow{2}{*}{$\begin{array}{l}\text { Total } \\
(\mathrm{n}=398)\end{array}$} & \multicolumn{3}{|l|}{ Group } & \multirow[t]{2}{*}{$\mathrm{p}$} \\
\hline & & $\begin{array}{l}A \\
(n=180)\end{array}$ & $\begin{array}{l}\mathrm{B} \\
(\mathrm{n}=164)\end{array}$ & $\begin{array}{l}C \\
(n=39)\end{array}$ & \\
\hline \multicolumn{5}{|l|}{ MDRD } & $<0.001$ \\
\hline $\mathrm{n}$ & 285 & 133 & 119 & 33 & \\
\hline Min & 2.36 & 2.36 & 2.60 & 8.42 & \\
\hline Max & 44.08 & 36.28 & 44.08 & 25.31 & \\
\hline Mean & 9.39 & 8.03 & 9.21 & 15.57 & \\
\hline $\mathrm{SD}$ & 5.08 & 4.28 & 4.50 & 5.59 & \\
\hline Median & 8.36 & 6.84 & 8.78 & 14.74 & \\
\hline \multicolumn{5}{|c|}{ Cockcroft-Gault } & $<0.001$ \\
\hline $\mathrm{n}$ & 269 & 125 & 114 & 30 & \\
\hline Min & 3.34 & 3.34 & 3.95 & 11.28 & \\
\hline Max & 67.69 & 48.70 & 67.69 & 38.11 & \\
\hline Mean & 12.87 & 11.36 & 12.57 & 20.31 & \\
\hline $\mathrm{SD}$ & 6.70 & 5.32 & 6.79 & 6.85 & \\
\hline Median & 11.66 & 10.19 & 11.72 & 18.97 & \\
\hline \multicolumn{5}{|l|}{ CKD-EPI } & $<0.001$ \\
\hline $\mathrm{n}$ & 235 & 113 & 95 & 27 & \\
\hline Min & 1.97 & 1.97 & 2.33 & 7.7 & \\
\hline Max & 35.66 & 35.66 & 15.99 & 23.81 & \\
\hline Mean & 8.52 & 7.52 & 7.97 & 14.72 & \\
\hline $\mathrm{SD}$ & 4.53 & 4.28 & 3.05 & 5.18 & \\
\hline Median & 7.56 & 6.43 & 7.73 & 14.57 & \\
\hline
\end{tabular}

ration $24.5 \pm 12.8 \%$. No statistically significant differences were observed between groups A, B and C. Body weight at the beginning of ESA therapy did not differ between the groups.

Mean serum creatinine at the start of ESA therapy was $7.2 \pm 2.86 \mathrm{mg} / \mathrm{dl}$. Mean creatinine clearance according to MDRD formula was $9.4 \pm 5.8 \mathrm{ml} / \mathrm{min}$, according to Cockcroft-Gault formula $12.87 \pm 6.7 \mathrm{ml} / \mathrm{min}$ and according CKD-EPI formula $8.52 \pm 4.53 \mathrm{ml} / \mathrm{min}$. The differences in creatinine concentration and clearance were statistically significant (table 4).

No differences in adverse events profile including serious adverse events, drug-related adverse events or cardiovascular events were observed between groups $\mathrm{A}, \mathrm{B}$ and C in our study.

\section{Discussion}

We demonstrated for the first time that in CEE countries the majority of patients with CKD receive ESA therapy shortly before or after start of dialysis treatment. The US Renal Data System Assessment study retrospectively examined hematocrit and erythropoietin use in CKD patients using Medicare data collected from across US states between 1994 and 2000 [17]. The study identified a close correlation between the extent of erythropoietin use and hematocrit, and found that both hematocrit values increased significantly after release of the US NKF-DOQI guidelines $[18,19]$. These findings suggested that, in the US, the guidelines might have had a favorable impact on outcomes in renal anemia. In contrast, a number of observational studies have indicated substantial deficiencies in the management of renal anemia in EU countries $[13,20,21]$. Therefore, we addressed the similar question of renal anemia treatment in large Eastern and Central European countries. The European Survey on Anaemia Management (ESAM) prospectively examined 14,527 CKD patients referred for dialysis across 14 countries, including Poland and Slovenia [13]. The Predialysis Survey on Anaemia Management (PRESAM) study is a retrospective observational study that included 4,333 patients, who commenced dialysis between September and November 1999 [20]. These surveys found that $>5 \%$ of patients had $\mathrm{Hb}<11 \mathrm{~g} / \mathrm{dl}$ and $80 \%$ of patients had $\mathrm{Hb}<10$ $\mathrm{g} / \mathrm{dl}$ when erythropoietin treatment was commenced, considerably lower than the NKF $[19,20]$ and EBPG recommendations [22]. Furthermore, fewer than $20 \%$ of patients had achieved target $\mathrm{Hb}$ when dialysis was instituted [20]. The ESAM study found that as few as 11 and $31 \%$ of patients had received erythropoietin before HD and CAPD, respectively [13]. These data suggest that clinicians may be underestimating the importance of identifying and adequately treating renal anemia, or that there is a lack of awareness of the EBPG recommendations for optimal treatment and target $\mathrm{Hb}$ concentrations. In the Dialysis Outcomes and Practice Patterns Study (DOPPS) [23], a prospective, observational study based on data collected from nationally representative samples of $\mathrm{HD}$ facilities that examine anemia management and outcomes, European countries included in the DOPPS were France, Germany, Italy, Spain and the UK (EuroDOPPS) [24]. In $2000,84 \%$ of prevalent HD patients were prescribed ESA. In our study, performed much later, early ESA therapy (more than 3 months before HD) was reported in approximately $10 \%$ of patients only [24]. This is in huge contrast to the ORAMA study [11], where almost all nondialysis patients (98\%) received ESA therapy during the prestudy period and at baseline, primarily s.c. epoetin beta (95\%). In comparison, in PRESAM, only $26 \%$ of patients were reported to have started ESA treatment before dialysis [20]. The decision about early introduction of ESA did not depend on the reason for CKD, patient's age or sex; how- 
ever, it seemed that patients who received early ESA therapy suffered longer from CKD than those who received ESA later. It appears that this phenomenon is related to the tight reimbursement policy. In general, we can only compare our data with the ORAMA study, where separate results for Eastern Europe were provided. In the prestudy period, patients treated early with ESA required lower doses of ESA than those who received ESA therapy shortly before or just after starting dialysis. This also appears to be related to the reimbursement policy in these countries. We also demonstrated for the first time that the diagnosis of CKD in the majority of patients (71\%) in CEE countries was established by the nephrologist or internist. In general, the diagnosis of CKD was made when patients had at least stage $3 \mathrm{CKD}$, in the majority of cases stage 4 . At the time of diagnosis, most patients had anemia. We calculated eGFR using three different formulae, including the novel CKD-EPI formula. In our study with patients with at least stage 3 CKD, eGFR using CKD-EPI was similar to MDRD; however, with the tendency to lower values particularly in group $\mathrm{C}$ (with the longest history of CKD, who started ESA at least 3 months before $\mathrm{HD})$. In general, on the basis of the reported eGFR at the time of diagnosis of CKD, it seems that there is still huge room for improvement of early detection of CKD and nephrological care. Results by Rayner et al. [25] from the DOPPS have shown that $81 \%$ of EuroDOPPS patients saw a nephrologist at least 1 month prior to starting dialysis (country range $72-87 \%$ ), and $76 \%$ saw a nephrologist more than 4 months prior to starting dialysis [24]. In PRESAM study, the majority of CKD patients had been under specific nephrologist control, but only $27 \%$ received ESA [21].

During the predialysis care, hematological parameters (hemoglobin, ferritin, serum iron concentration and transferrin saturation) remain stable. At start of dialysis mean hemoglobin value was lower than at the beginning of the disease $(9.26 \pm 1.7$ vs. $10.3 \pm 2.3 \mathrm{~g} / \mathrm{dl}$, respectively). At the beginning of ESA therapy, the mean hemoglobin value was $9.24 \pm 1.4 \mathrm{~g} / \mathrm{dl}$, similar to the low mean hemoglobin concentration of $9.4 \mathrm{~g} / \mathrm{dl}$ displayed by new ESRD patients when initiating HD in EuroDOPPS in 1998-2000. This underscores the failure of pre-ESRD health care programs to adequately address the anemia management needs in this patient population. However, in the ORAMA study, 3 out of 5 nondialysis patients had mean prestudy $\mathrm{Hb}$ values above the EBPG target of 11 $\mathrm{g} / \mathrm{dl}$, which is a higher rate than among dialysis patients [11]. Patients who entered the study had already been treated with ESA, and mean hemoglobin at the baseline visit was higher than at ESA start $(11.04 \pm 1.38 \mathrm{~g} / \mathrm{dl})$. During all subsequent study visits, mean hemoglobin value in the whole study group was stable and varied from 11.04 to $11.26 \mathrm{~g} / \mathrm{dl}$. It was consistent with the new European Best Practice Guidelines [26], which were the first to address this issue in the post-TREAT era [8]. Now, it is strongly recommended that, for diabetic CKD patients or CKD patients with comorbidities, a new treatment target of 10-12 g/dl (and not the historical target of $11-12 \mathrm{~g} / \mathrm{dl}$ ) is warranted. Group A patients entered the study with lower hemoglobin concentration than the remaining groups, as expected. In this respect, it is difficult to compare our data with the ORAMA study [11], because we look at the incident HD patients and their retrospective data, whereas in the ORAMA trial prevalent HD or CKD patients were randomized to either standard clinical care or computerized clinical decision support [11]. Nevertheless, the mean hemoglobin in Eastern Europe was $10.6 \mathrm{~g} / \mathrm{dl}$ compared with 11.8 $\mathrm{g} / \mathrm{dl}$ in Western Europe in the HD population in the ORAMA trial [11].

In general, patients with increased residual renal function as in group C may also demonstrate more endogenous erythropoietin production and therefore a lesser need for ESA therapy. However, no statistically significant differences were observed between groups $\mathrm{A}, \mathrm{B}$ and $\mathrm{C}$ with regard to hemoglobin, ferritin and serum iron. The differences in ESA dose might be attributed to the better residual renal function in group $\mathrm{C}$, less pronounced subclinical inflammation due to better kidney function, better nephrological care (center effect?), or slightly, although not significantly better iron supplementation.

The majority of patients received iron supplementation $(86 \%)$ and folic acid therapy (68\%). No differences between groups $\mathrm{A}, \mathrm{B}$ and $\mathrm{C}$ were noted. In the EuroDOPPS, the fraction of HD patients who were prescribed i.v. iron within a 4-month data collection interval in the year 2000 ranged from $43 \%$ of patients in Italy to $71 \%$ in Germany [24]. In the ORAMA trial, $64 \%$ of the population studied received iron therapy in Eastern Europe, similar to 66\% in Western Europe [11]. In the CKD population, Eastern Europe was represented only by Bulgaria, where iron supplementation was given to $60 \%$ of the studied patients, while only in $37 \%$ in Western Europe. In the GAIN trial, all countries had $46-74 \%$ of patients on iron therapy with the exception of Greece (25.6\%) and Turkey (23.2\%); however, the detailed data are unavailable [12]. No data on iron therapy are available in the ESAM study. The authors provided only data on 
iron status (adequate, functional or absolute iron deficiency) in the population studied without detailed results for specific countries [13]. In our study, $31 \%$ of patients received blood transfusion, and it was shown that patients who did not receive ESA before dialysis required more transfusions and received more blood than those who had been treated with ESA before dialysis. There are no data provided by ORAMA trial investigators [11, 27], ESAM [13] or GAIN [12].

In conclusion, in CEE countries renal anemia therapy with ESA is started shortly before or after start of HD. The subcutaneous administration route of NeoRecormon was most frequently used in standard practice during the period of the study. Prestudy and baseline data reported in our study highlight important differences in standard care in Eastern Europe. However, paradoxically, due to tight reimbursement policy we foresee the clinical implications of the TREAT trial for the CKD population.

\section{Acknowledgements}

\section{Study Investigators}

Latvia: Regina Baufale, Natalija Bidzina, Inara Busmane, Vera Grotkere, Tatjana Kozlova, Guna Legzdina, Linda Micule, Gita Saumane-Baza, Aldis Spudass, Ligita Zepa.

Poland: Danuta Antczak-Jędrzejczak, Hanna AugustyniakBartosik, Wacław Bentkowski, Alicja Brylowska-Markowicz, Edward Ciechanowicz-Lewkowicz, Krzysztof Dziewanowski, Jacek Felisiak, Piotr Firczyk, Mirosław Grzeszczyk, Zbigniew Hruby, Marzena Janas, Krzysztof Jarzębski, Marian Klinger, Arkadiusz Lewartowski, Justyna Matulewicz-Gilewicz, Olech Mazur, Danuta Ostrowska-Reguła, Marita Piechowska, Jan Pulchny, Roman Radziszewski, Bolesław Rutkowski, Jacek Sobolewski, Roman Stankiewicz, Anna Struś, Arkadiusz Szwedowicz, Ewa Trafidło, Jerzy Wiatrow, Rafał Wnuk, Danuta Zaremba-Drobnik, Danuta Zwolińska.

Serbia: Jovan Bakovic, Ivana Budosan, Vidojko Djordjevic, Rosa Jelacic, Dragisa Jevremovic, Ljiljana Komadina, Djoko Maksic, Igor Mitic, Vidosava Nesic, Svetlana Pejanovic, Steva Pljesa, Nenad Rakic, Miomir Stojanovic, Ljubisa Veljancic.

\section{References}

1 National Kidney Foundation (NKF) Kidney Disease Outcome Quality Initiative (K/ DOQI) Advisory Board: K/DOQI clinical practice guidelines for chronic kidney disease: evaluation, classification, and stratification. Kidney Disease Outcome Quality Initiative. Am J Kidney Dis 2002;39(suppl 2):S1-S246.

$\checkmark 2$ Eschbach JW, Adamson JW: Anaemia of end-stage renal disease (ESRD). Kidney Int 1985;28:1-5.

- 3 Foley RN, Parfrey PS, Harnett JD, Kent GM, Murray DC, Barre PE: The impact of anaemia on cardiomyopathy, morbidity, and mortality in end-stage renal disease. Am J Kidney Dis 1996;28:53-61.

$\checkmark 4$ Portoles J, Torralbo A, Martin P, Rodrigo J, Herrero JA, Barrientos A: Cardiovascular effects of recombinant human erythropoietin in predialysis patients. Am J Kidney Dis 1997; 29:541-548.

5 Eschbach JW, Aquiling T, Haley NR, Fan $\mathrm{MH}$, Blagg CR: The long-term effects of recombinant human erythropoietin on the cardiovascular system. Clin Nephrol 1992; 38(suppl 1):S98-S103.

-6 Singh AK, Szczech L, Tang KL, Barnhart H, Sapp S, Wolfson M, Reddan D: CHOIR Investigators. Correction of anemia with epoetin alfa in chronic kidney disease. N Engl J Med 2006;355:2085-2098.
7 Drueke TB, Locatelli F, Clyne N, Eckardt KU, Macdougall IC, Tsakiris D, Burger HU, Scherhag A, CREATE Investigators: Normalization of hemoglobin level in patients with chronic kidney disease and anemia. N Engl J Med 2006;355:2071-2084.

-8 Pfeffer MA, Burdmann EA, Chen CY, Cooper ME, de Zeeuw D, Eckardt KU, Feyzi JM, Ivanovich P, Kewalramani R, Levey AS, Lewis EF, McGill JB, McMurray JJ, Parfrey P, Parving HH, Remuzzi G, Singh AK, Solomon SD, Toto R: TREAT Investigators. A trial of darbepoetin alfa in type 2 diabetes and chronic kidney disease. N Engl J Med 2009; 361:2019-2032.

-9 McClellan WM, Flanders WD, Gutman RA: Variable mortality rates among dialysis treatment centres. Ann Intern Med 1992;117: 332-336.

10 Hulbert-Shearon TE, Loos E, Ashby VB, Port FK, Wolfe RA: USRDS 1999 Unit-Specific Reports for Dialysis Patients: A Summary. University of Michigan, Ann Arbor, 1999.

11 Wiecek A, Covic A, Locatelli F, Macdougall IC, on behalf of the ORAMA Study Group: Renal anaemia: comparing current eastern and western European management practice (ORAMA). Ren Fail 2008;30:267-276.

$\checkmark 12$ Rath T, Mactier RA, Weinreich T, Scherhag AW, GAIN Investigators: Effectiveness and safety of recombinant human erythropoietin beta in maintaining common haemoglobin targets in routine clinical practice in $\mathrm{Eu}$ rope: the GAIN study. Curr Med Res Opin 2009;25:961-970.
13 European Survey on Anaemia Management (ESAM). Nephrol Dial Transplant 1999; 14(suppl 5):1-76

14 Cockcroft DW, Gault MH: Prediction of creatinine clearance from serum creatinine. Nephron 1976;16:31-41.

15 Modification of Diet in Renal Disease Study Group: Creatinine filtration, secretion and excretion during progressive renal disease. Kidney Int 1989;36:S73-S80.

16 Levey AS, Stevens LA, Schmid CH, Zhang YL, Castro AF 3rd, Feldman HI, Kusek JW, Eggers P, Van Lente F, Greene T, Coresh J, CKD-EPI (Chronic Kidney Disease Epidemiology Collaboration): A new equation to estimate glomerular filtration rate. Ann Intern Med 2009;150:604-612

17 Collins AJ, Roberts TL, St Peter WL, Chen SC, Ebben J, Constantini E: United States Renal Data System assessment of the impact of the National Kidney Foundation - Dialysis Outcomes Quality Initiative guidelines. Am J Kidney Dis 2002;39:784-795.

18 National Kidney Foundation: NKF-K/ DOQI clinical practice guidelines and clinical practice recommendations for anemia in chronic kidney disease in adults. Am J Kidney Dis 2006;47(suppl 3):16-85.

19 National Kidney Foundation: NKF-KDOQI clinical practice guideline and clinical practice recommendations for anemia in chronic kidney disease: 2007 update of hemoglobin target. Am J Kidney Dis. 2007;50:471-530. 
-20 Valderrabano F, Horl WH, Macdougall IC, Rossert J, Rutkowski B, Wauters JP: PRE-dialysis survey on anaemia management. Nephrol Dial Transplant 2003;18:89-100.

21 Jacobs C, Frei D, Perkins AC: Results of the European Survey on Anaemia Management 2003 (ESAM 2003): current status of anaemia management in dialysis patients, factors affecting epoetin dosage and changes in anaemia management over the last 5 years. Nephrol Dial Transplant 2005;20(suppl 3): 3-24.

-22 Valderrabano F, Horl WH, Jacobs C, et al: European best practice guidelines 1-4: evaluating anaemia and initiating treatment. Nephrol Dial Transplant 2000;15(suppl 4): 8-14.
3 Pisoni RL, Bragg-Gresham JL, Young EW, et al: Anemia management and outcomes from 12 countries in the Dialysis Outcomes and Practice Patterns Study (DOPPS). Am J Kidney Dis 2004;44:94-111.

24 Locatelli F, Pisoni RL, Combe C, et al: Anaemia in haemodialysis patients of five European countries: association with morbidity and mortality in the Dialysis Outcomes and Practice Patterns Study (DOPPS). Nephro Dial Transplant 2004;19:121-132.

25 Rayner HC, Pisoni RL, Bommer J, Canaud B, Hecking E, Locatelli F, Piera L, BraggGresham JL, Feldman HI, Goodkin DA, Gillespie B, Wolfe RA, Held PJ, Port FK: Mortality and hospitalization in haemodialysis patients in five European countries: results from the Dialysis Outcomes and Practice Patterns Study (DOPPS). Nephrol Dial Transplant 2004;19:108-120.
26 Locatelli F, Aljama P, Canaud B, et al: On behalf of the Anaemia Working Group of European Renal Best Practice (ERBP). Target haemoglobin to aim for with erythropoiesisstimulating agents: a position statement by ERBP following publication of the Trial to Reduce Cardiovascular Events with Aranesp(R) Therapy (TREAT) Study. Nephrol Dial Transplant 2010;25:2846-2850.

27 Locatelli F, Covic A, Macdougall IC, Wiecek A, on behalf of the ORAMA Study Group: ORAMA: a study to investigate EBPG impact on renal anaemia - design and baseline data. J Nephrol 2008;21:592-602. 